\title{
Non-enzymatic Reduction of Hydrogen Peroxide Sensor Based on (Polyaniline-polystyrene Sulphonate) - Carboxylated Graphene Modified Graphite Electrode
}

\author{
S. Prasannakumar, ${ }^{a}$ R. Manjunatha, ${ }^{a}$ C. Nethravathi, ${ }^{b}$ G. S. Suresh, ${ }^{a, c, *}$ \\ M. Rajamathi ${ }^{b}$ and T. V. Venkatesha ${ }^{d}$ \\ ${ }^{a}$ Chemistry Research Centre, S.S.M.R.V. Degree College, Jayanagar, Bangalore-560041, India \\ ${ }^{b}$ Materials Research Group, Department of Chemistry, St. Josephs's College, 36 \\ Lalbagh Road, Bangalore-560027, India \\ ${ }^{c}$ Department of Chemistry, NMKRV College for Women, Jayanagar, Bangalore-560011, India \\ ${ }^{d}$ Department of Chemistry, Kuvempu University, Jnanasahyadri, Shimoga-577451, India
}

Received 6 April 2012; accepted 16 November 2012

\begin{abstract}
A modified electrode is fabricated by the electrodeposition of polyaniline-polystyrene sulphonate composite onto the carboxylated graphene modified graphite electrode for the detection of hydrogen peroxide $\left(\mathrm{H}_{2} \mathrm{O}_{2}\right)$. The modified electrode displayed excellent catalytic response to the reduction of hydrogen peroxide in neutral $\mathrm{pH}$. It was found that the presence of carboxylated graphene in the sensor system could effectively increase the electron transfer rate and stability. The modified electrode was characterized by cyclic voltammetry, electrochemical impedance spectroscopy and atomic force microscopy. Chronoamperometric studies showed the linear relationship between the reduction peak current and the concentration of $\mathrm{H}_{2} \mathrm{O}_{2}$ in the range 25 to $350 \mu \mathrm{M}(R=-$ $0.995)$ with the detection limit of $1 \times 10^{-6} \mathrm{~mol} / \mathrm{L}(S / N=3)$. Further, electrochemical analysis of $\mathrm{H}_{2} \mathrm{O}_{2}$ in the presence of common interferents such as dopamine, uric acid and ascorbic acid with the modified electrode reveals that there is no overlapping signal from the interferents.
\end{abstract}

Keywords: carboxylated graphene, electropolymerizaton, hydrogen peroxide, polyaniline, poly(styrene sulphonate).

\section{Introduction}

Graphene has been considered as one of the thinnest materials in our universe [1]. Graphene, a 2-D, single layer of carbon atoms with a hexagonal arrangement of $\mathrm{sp}^{2}$ hybridization has attracted a tremendous amount of interest among

\footnotetext{
* Corresponding author. E-mail: sureshssmrv@yahoo.co.in
} 
researchers. It can be seen as the basic building block for graphitic materials. The characteristic properties of graphene include fast electron transportation, high thermal conductivity, excellent mechanical strength and good biocompatibility. The promising properties together with the ease of processibility and functionalizability make graphene-based materials ideal candidates for the application in many areas including electrochemical sensing and biosensing of analytes like dopamine, ascorbic acid, uric acid and NADH [2-4]. Graphenebased electrodes have been shown to exhibit excellent electron transfer promoting ability for some enzyme-based biosensors [1, 5]. Although the poor solubility of graphene essentially makes it difficult to construct graphene based electronic devices, considerable efforts have been made to accomplish the above purposes. The oxidation procedure used for purification of graphene, mainly to remove metal catalysts and amorphous carbon, also results in partial oxidation of the carbon atom to produce oxygen containing carboxylic acid groups in the open end of the graphene [4]. These groups are negatively charged in aqueous solution and can interact with positively charged polyelectrolyte.

Electrically conducting polymer has attracted attention for application in various electrochemical devices including capacitors, photovoltaic cells, batteries and biosensors [6-8]. Polyaniline is one of the most widely used conducting polymers due to its easy synthesis, environment stability and simple acid/base dopingdedoping chemistry. Polyaniline reveals redox functionality only in acidic media; this feature limits its use. Incorporating polyanions into the polymer, switches the redox activity of the polyaniline to neutral $\mathrm{pH}$ [9]. It is well known that sensor and biosensors arrays based on polyaniline possess superior transducing ability and excellent interface-free performance characteristics. These sensors have been tested for the assay of glucose, urea, and ascorbic acid [10-12]. On the other hand the positively charged polyaniline can be electrodeposited on negatively charged carboxylated graphene effectively.

The detection of hydrogen peroxide has attracted considerable attention because it plays an important role in food industry, clinical diagnosis and environmental monitoring. The hydrogen peroxide detection is also of special interest in terms of tracking many biological targets such as glucose and lactose. Many techniques have been employed for the determination of $\mathrm{H}_{2} \mathrm{O}_{2}$, such as titrimetry, spectrometry and chemiluminescence [13]. Among the various analytical techniques, electrochemical enzyme biosensor is the most tempting due to its simplicity, high selectivity of the biological recognition elements and high sensitivity of electrochemical transduction process [14-16]. However, the instability of enzyme activity, due to factors such as temperature, $\mathrm{pH}$ and oxygen restricts the use of enzyme-based sensors [17]. Various electrodes are fabricated for the determination of $\mathrm{H}_{2} \mathrm{O}_{2}$ without enzymes, few to cite [18-20]

This paper demonstrates a facile approach for developing an enzyme-less $\mathrm{H}_{2} \mathrm{O}_{2}$ sensor based on electro polymerized polyaniline-polystyrene sulphonate (PANIPSS) composite on carboxylated graphene modified graphite electrode in $0.1 \mathrm{M}$ phosphate buffer solution at $\mathrm{pH}$ 7.0. The electrochemical behavior of the modified electrode towards the determination of $\mathrm{H}_{2} \mathrm{O}_{2}$ was investigated by cyclic 
voltammetry, electrochemical impedance spectroscopy and chronoamperommetry.

\section{Experimental details \\ Reagents}

Hydrogen peroxide $30 \%(w / v)$ and aniline were procured from SRL India. Polystyrenesulphonate (PSS) $\left(M_{\mathrm{w}}: 70,000\right)$, ascorbic acid, dopamine and uric acid were purchased from Sigma Aldrich and used as received. Phosphate buffer saline (PBS) was prepared using stock solutions of $0.1 \mathrm{M} \mathrm{K}_{2} \mathrm{HPO}_{4}, 0.1 \mathrm{M}$ $\mathrm{KH}_{2} \mathrm{PO}_{4}$ and $0.1 \mathrm{M} \mathrm{KCl}$. The $\mathrm{pH}$ was adjusted using $0.1 \mathrm{M} \mathrm{HCl}$ and $0.1 \mathrm{M}$ $\mathrm{NaOH}$. All other chemicals used were of analytical grade and used without further purification. All solutions were prepared with milli- $Q$ water.

\section{Electrochemical measurements}

Cyclic voltammetry, chronoamperometry, and electrochemical impedance spectroscopy were carried out with Versastat 3 (Princeton applied research, USA). All electrochemical measurements were carried out in a three electrode electrochemical cell with Gr/(PANI-PSS) or Gr/carboxylated graphene-(PANIPSS) electrode as working electrode, saturated calomel (SCE) as reference electrode and platinum as auxiliary electrode.

\section{Preparation of carboxylated graphene}

Graphene sheets were first prepared by solvothermal reduction of colloidal suspension of graphite oxide according to the procedure described elsewhere [21]. In brief, graphite powder was added to cold and concentrated $\mathrm{H}_{2} \mathrm{SO}_{4}$. $\mathrm{KMnO}_{4}$ was added with stirring and cooling. The temperature was increased to $35^{\circ} \mathrm{C}$ and the mixture was maintained at this temperature for 30 minutes. Pure water was then added and the temperature was increased to $98{ }^{\circ} \mathrm{C}$; the mixture was maintained at that temperature for 15 minutes. The reaction was terminated by adding pure water followed by $30 \% \mathrm{H}_{2} \mathrm{O}_{2}$ solution. The resulting product is graphite oxide (GO). GO thus obtained was dispersed in water and the colloidal dispersion was subjected to solvothermal reduction in a teflon-lined stainless steel autoclave at $200{ }^{\circ} \mathrm{C}$ to form graphene sheets. The conductivity of the graphene oxide (graphite oxide) is much lesser than that of reduced graphene oxide (graphene) (graphene oxide sheets reduced to obtain a high conductive graphene sheets). Graphene oxide showed a resistivity of about $188-413 \mathrm{k} \Omega / \mathrm{m}$ [22]. However, the resistivity decreases drastically to $\sim 15 \mathrm{k} \Omega / \mathrm{m}$ after high thermal reduction with alcohol. Similarly electrical conductivity of graphene is 10,000 fold increased after reduction of graphene oxide [23]. Graphene sheets thus obtained were refluxed with concentrated $\mathrm{HNO}_{3}$ for $5 \mathrm{~h}$ so that $\mathrm{COO}^{-}$is introduced at the edges of graphene sheet and the product obtained is hence forth referred to as carboxylated graphene. The carboxylated graphene was characterized by FTIR and pXRD and reported in our previous paper [4]. 


\section{Fabrication of Gr/carboxylated graphene-(PANI-PSS) electrode}

An electrode was made by inserting a graphite cylinder of $6 \mathrm{~mm}$ diameter in the hole of a Teflon bar with the same internal diameter. Electrical contact was made with a copper wire through the centre of the Teflon bar. Prior to the modification, the graphite electrode was polished to get a mirror shining surface using different grades of emery paper, i.e., $1000,800,6 / 0,4 / 0$ and finally with $2 / 0$. It was then ultrasonicated for several minutes and rinsed with milli- $Q$ water. Carboxylated graphene $(8 \mathrm{mg} / \mathrm{mL})$ was dispersed in pure water. $10 \mu \mathrm{L}$ dispersion of carboxylated graphene was casted onto the polished graphite electrode and dried at ambient temperature. This electrode was dipped in $20 \mathrm{~mL}$ of the solution containing $0.025 \mathrm{M}$ aniline and $15 \mathrm{mg} / \mathrm{mL}$ polystyrene sulphonate in $0.025 \mathrm{M}$ $\mathrm{H}_{2} \mathrm{SO}_{4}$ and subjected to electrochemical polymerization by continuous potential cycling in the potential range of -0.2 to $0.8 \mathrm{~V}$. A green colour deposit was seen on the surface of the electrode. After polymerization, Gr/carboxylated graphene(PANI-PSS) electrode (modified electrode) was washed with water and stored in PBS of $\mathrm{pH} 7$ when not in use.

\section{Results and Discussion}

Influence of carboxylated graphene dispersion and the aniline solution on sensor fabrication

The carboxylated graphene content is one of the crucial factors to be considered for the development of $\mathrm{H}_{2} \mathrm{O}_{2}$ sensor. We compared the calibration plots for $\mathrm{H}_{2} \mathrm{O}_{2}$ at different electrodes by adjusting the content of the carboxylated graphene in the dispersion. Fig. 1 shows the graphite electrodes modified with carboxylated graphene with varying the concentration of graphene in phosphate buffer solution at $-0.18 \mathrm{~V}$ towards the reduction of $\mathrm{H}_{2} \mathrm{O}_{2}$.

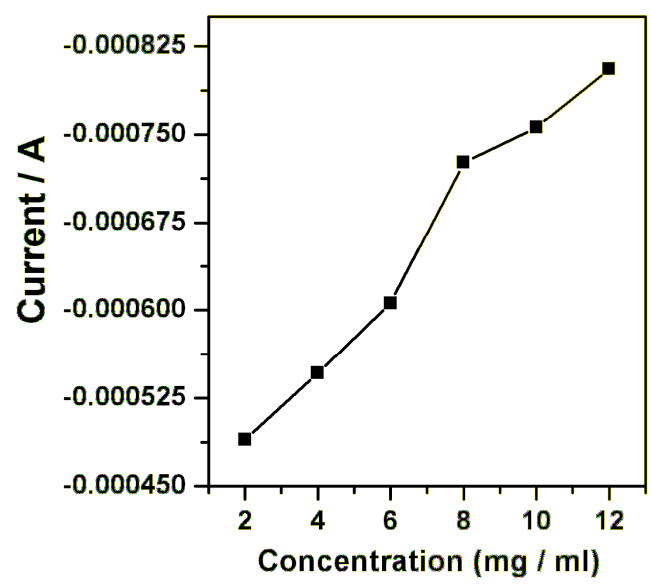

Figure 1. Graphite electrodes modified with carboxylated graphene with varying concentration of graphene in phosphate buffer solution containing $0.1 \mathrm{M} \mathrm{KCl}$ at $-0.18 \mathrm{~V}$ towards $6 \mathrm{mM} \mathrm{H}_{2} \mathrm{O}_{2}$.

The sensitivity and cathodic current increased with carboxylated graphene loading from 2 to $8 \mathrm{mg} / \mathrm{mL}$. When we increased the concentration further the sensitivity and cathodic current increased slightly, but the stability of the 
carboxylated film was rather poor. Hence $8 \mathrm{mg} / \mathrm{mL}$ were selected for all our experiments. Aniline concentration of $0.025 \mathrm{M}$ was selected for all our experiments. This is because, when the concentration of aniline went beyond $0.025 \mathrm{M}$, the experimental results were not satisfactory. This could be due the polyaniline film formed which seemed to be thick with the decreased sensitivity and increased response time.

\section{Electrodepositon of PANI-PSS composite on carboxylated graphene modified graphite electrode}

Fig. 2 shows the electrodeposition of PANI-PSS onto the carboxylated graphene modified graphite electrode by cyclic voltammetry. The potential was swept from -0.2 to $0.8 \mathrm{~V}$ (vs. SCE), as polyaniline is redox active within this region at acidic $\mathrm{pH}$.

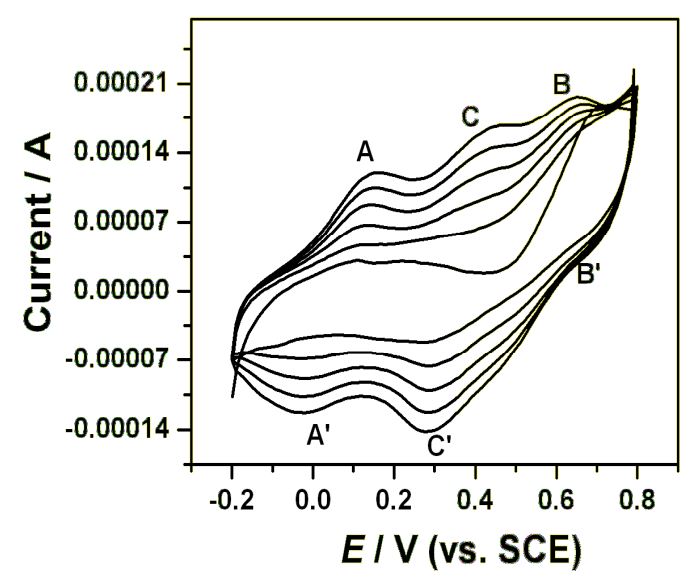

Figure 2. Typical cyclic voltammograms of PANI-PSS composite synthesized between -0.2 to $0.8 \mathrm{~V}$ for 5 cycles at carboxylated graphene modified graphite electrode. Scan rate: $0.005 \mathrm{~V} / \mathrm{s}$.

It is generally agreed that PANI exists in three different base forms: leucoemeraldine (LEB, fully reduced), emeraldine (EB, half-oxidised) and pernigraniline (PNB, fully oxidized). The only electrically conducting form is, however, the emeraldine salt form (ES), which is the protonated form of EB. The $\mathrm{CV}$ is typical for PANI-emeraldine salt (ES) with the main peaks A and B corresponding to the transformation of leucoemeraldine base (LB) to ES and ES to pernigraniline salt (PS), respectively. On the reverse scan, peaks $\mathrm{B}^{\prime}$ and $\mathrm{A}^{\prime}$ correspond to the conversion of PS to ES and ES to LB, respectively. The presence of a small redox peak around $0.35 \mathrm{~V}\left(\mathrm{C}\right.$ and $\left.\mathrm{C}^{\prime}\right)$ is associated with the formation of benzoquinone and hydroquinone as the side products. It was also observed that the current response was increased on the subsequent scans indicating the formation of the polymer on carboxylated graphene modified graphite electrode. The thickness $(d)$ of the deposited PANI-PSS composite film on Gr/carboxylated graphene was estimated from the charge necessary to convert the leucoemeraldine form from PANI to emeraldine form (using the area under the first redox process in the voltammograms). The following equation was used to calculate the thickness of the film [24]. 


$$
d=Q M_{\mathrm{w}} / z F A \rho
$$

where, $Q$ is the charge under first cyclic voltammetric peak, $A$ is the area of the electrode $\left(0.28 \mathrm{~cm}^{2}\right), \rho$ is the specific density of aniline $\left(1.02 \mathrm{~g} / \mathrm{cm}^{3}\right), M_{\mathrm{w}}$ is the molecular weight of aniline $(93.13 \mathrm{~g} / \mathrm{Mol}), z$ is the number of electron / aniline units (0.5), and $\mathrm{F}$ is the Faradays constant. The thickness of the film was estimated to be $5 \mu \mathrm{m}$.

\section{Characterization of the Gr/carboxylated graphene-(PANI-PSS) electrode using cyclic voltammetry and electrochemical impedance spectroscopy}

The cyclic voltammetric behavior of the modified electrode after deposition of PANI-PSS was examined using $\mathrm{Fe}(\mathrm{CN})_{6}{ }^{4-/ 3-}$ as an electrochemical probe, as illustrated in Fig. 3a. The oxidation of $\mathrm{Fe}(\mathrm{CN})_{6}{ }^{4-}$ at $\mathrm{Gr} / \mathrm{PANI}-\mathrm{PSS}$ electrode is quasireversible with formal potential of $0.185 \mathrm{~V}$ and peak to peak separation of $0.068 \mathrm{~V}$ at a scan rate of $0.005 \mathrm{~V} / \mathrm{s}$. After modification with $\mathrm{Gr} /$ carboxylated graphene-(PANI-PSS), CV shows a pair of quasireversible peaks at a formal potential of $0.192 \mathrm{~V}$ and the peak to peak separation of $0.049 \mathrm{~V}$. The oxidation peak potential was observed at $0.215 \mathrm{~V}$. In addition, the peak current on the modified electrode was observed to be more as compared to Gr/PANI-PSS electrode. This increase in the peak current on the modified electrode can be attributed to the increase of the effective surface area due to the graphene present on the surface of graphite.
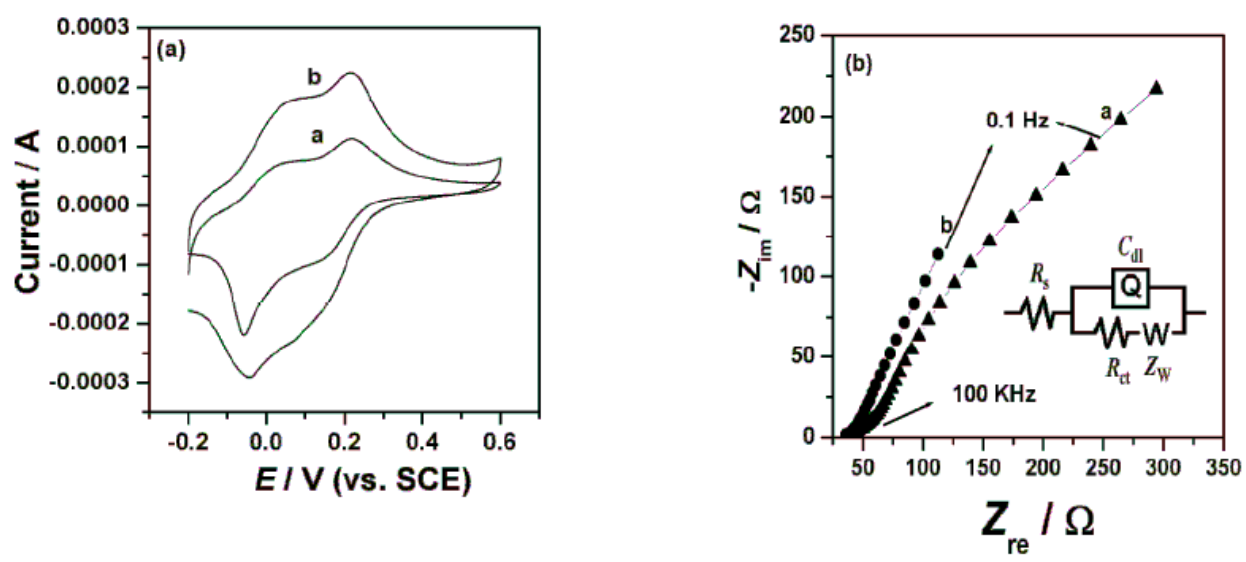

Figure 3. Cyclic voltammograms of Gr/(PANI-PSS) electrode (a) and Gr/carboxylated graphene-(PANI-PSS) electrode (b). (a) in $1 \mathrm{mM} \mathrm{Fe}(\mathrm{CN})_{6}{ }^{4-/ 3-}$ in phosphate buffer solution of $\mathrm{pH} 7.0$ at a scan rate of $0.01 \mathrm{Vs}^{-1}$; (b) Nyquist impedance plots of $\mathrm{Gr} /$ (PANI-PSS) electrode (a) and Gr/carboxylated graphene-(PANI-PSS) electrode (b). The frequency ranges from $100 \mathrm{KHz}$ to $0.1 \mathrm{~Hz}$ with the amplitude of $5 \mathrm{mV}$. The supporting electrolyte is $0.1 \mathrm{M}$ phosphate buffer containing $0.1 \mathrm{M} \mathrm{KCl}$.

Electrochemical impedance spectroscopy is an effective method for probing the features of surface-modified electrodes. Fig. 3b shows that at Gr/(PANI-PSS) electrode the impedance spectrum was composed of a semicircle and a straight tail line. The semicircle part at high frequency corresponds to limited electrontransfer process and the linear part at low frequency originates from the mass 
transfer limitation of $\mathrm{Fe}(\mathrm{CN})_{6}{ }^{4-/ 3}$. Interestingly after modifying the graphite electrode with carboxylated graphene and PANI-PSS the semicircle is not observed and only a straight line was observed suggesting the presence of microscopically rough and porous surface. This indicates that the impedance offered by modified electrode-electrolyte interface for charge transfer process is less when compared to the Gr/(PANI-PSS) electrode [25]. The spectra were fitted to equivalent Randles circuit which is shown in the inset of Fig. 3 (b). The circuit includes the Ohmic resistance of the electrolytic solution $\left(R_{\mathrm{S}}\right)$, the Warburg impedance $\left(Z_{\mathrm{w}}\right)$ resulting from the ions from electrolytic solution to the electrode, the double layer capacitance $\left(C_{\mathrm{dl}}\right)$ and the interfacial charge transfer resistance $\left(R_{\mathrm{ct}}\right)$. The two components $R_{\mathrm{ct}}$ and $C_{\mathrm{dl}}$ depend on the dielectric and insulating features at the interface. In the Randles circuit model, both $R_{\mathrm{ct}}$ and $Z_{\mathrm{w}}$ are in parallel to the $C_{\mathrm{dl}}$. The values of the fitting parameters of the electrode are summarized in Table 1 . The $R_{\mathrm{ct}}$ value of the Gr/carboxylated graphene-(PANIPSS) electrode is much smaller than that of the Gr/(PANI-PSS) electrode suggesting that the Gr/carboxylated graphene-(PANI-PSS) electrode was facilitating the easy electron transfer. Further, the $C_{\mathrm{dl}}$ value for the Gr/carboxylated graphene-(PANI-PSS) electrode is much higher than that for the Gr/(PANI-PSS) electrode revealing that the ferricyanide ions can easily diffuse through the Gr/carboxylated graphene-(PANI-PSS) electrode layer.

Table 1. EIS data of Gr/(PANI-PSS) and Gr/carboxylated graphene-(PANI-PSS) electrodes in $1 \mathrm{mM} \mathrm{Fe}(\mathrm{CN})_{6}^{4-/ 3-}$.

\begin{tabular}{ccccc}
\hline \multicolumn{1}{c}{ Electrode } & $\boldsymbol{R}_{\mathbf{s}} / \mathbf{\Omega}$ & $\boldsymbol{R}_{\mathbf{c t}} / \mathbf{\Omega}$ & $\boldsymbol{C}_{\mathrm{dl}} / \mathbf{m F}$ & $\boldsymbol{Z}_{\mathbf{w}} / \mathbf{\Omega}$ \\
\hline $\begin{array}{l}\text { Gr/(PANI-PSS) electrode } \\
\begin{array}{l}\text { Gr/carboxylated graphene- } \\
\text { (PANI-PSS) electrode }\end{array}\end{array}$ & 42.16 & 9.916 & 0.00077 & $1.56 \times 10^{-12}$ \\
& 37.81 & 0.01 & 0.01 & 0.0032 \\
\hline
\end{tabular}

\section{Electrocatalytic reduction of $\mathrm{H}_{2} \mathrm{O}_{2}$ at Gr/carboxylated graphene-(PANI-PSS) electrode}

To investigate the electrocatalytic activity of Gr/carboxylated graphene-(PANIPSS) electrode, electrochemical catalytic reduction of $\mathrm{H}_{2} \mathrm{O}_{2}$ was investigated by cyclic voltammetry. At unmodified carbon electrodes no reduction peak was observed for $\mathrm{H}_{2} \mathrm{O}_{2}$ in the potential range 0.4 to $-0.6 \mathrm{~V}$, suggesting that the carbon electrode was inactive to the direct reduction (curve not shown). However, at Gr/carboxylated graphene-(PANI-PSS) electrode, Fig. 4 shows that the reduction peak current at about $-0.18 \mathrm{~V}$ was greatly enhanced in the presence of $6 \mathrm{mM}$ $\mathrm{H}_{2} \mathrm{O}_{2}$. 


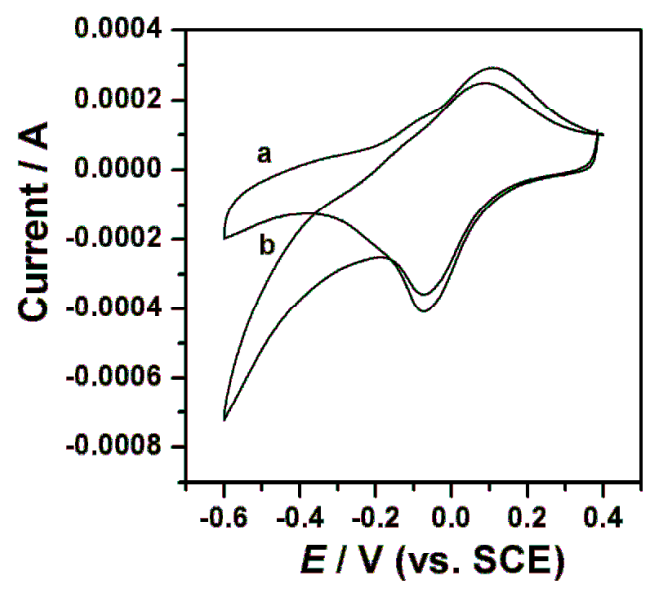

Figure 4. Cyclic voltammograms of Gr/carboxylated graphene-(PANI-PSS) modified electrode in the absence (a) and presence (b) of $6 \mathrm{mM} \mathrm{H}_{2} \mathrm{O}_{2}$ in phosphate buffer solution of $\mathrm{pH} 7.0$ containing $0.1 \mathrm{M} \mathrm{KCl}$ at the scan rate of $0.01 \mathrm{Vs}^{-1}$.

\section{Effect of increasing concentration and scan rate at Gr/carboxylated graphene- (PANI-PSS) electrode}

The cyclic voltammogram responses for a series of $\mathrm{H}_{2} \mathrm{O}_{2}$ solution with various concentrations are shown in Fig. 5a. With the addition of $\mathrm{H}_{2} \mathrm{O}_{2}$ there was an increase in the reduction peak current linearly. The above result indicated that reduction of $\mathrm{H}_{2} \mathrm{O}_{2}$ takes place at $\mathrm{Gr} /$ carboxylated graphene-(PANI-PSS) electrode.
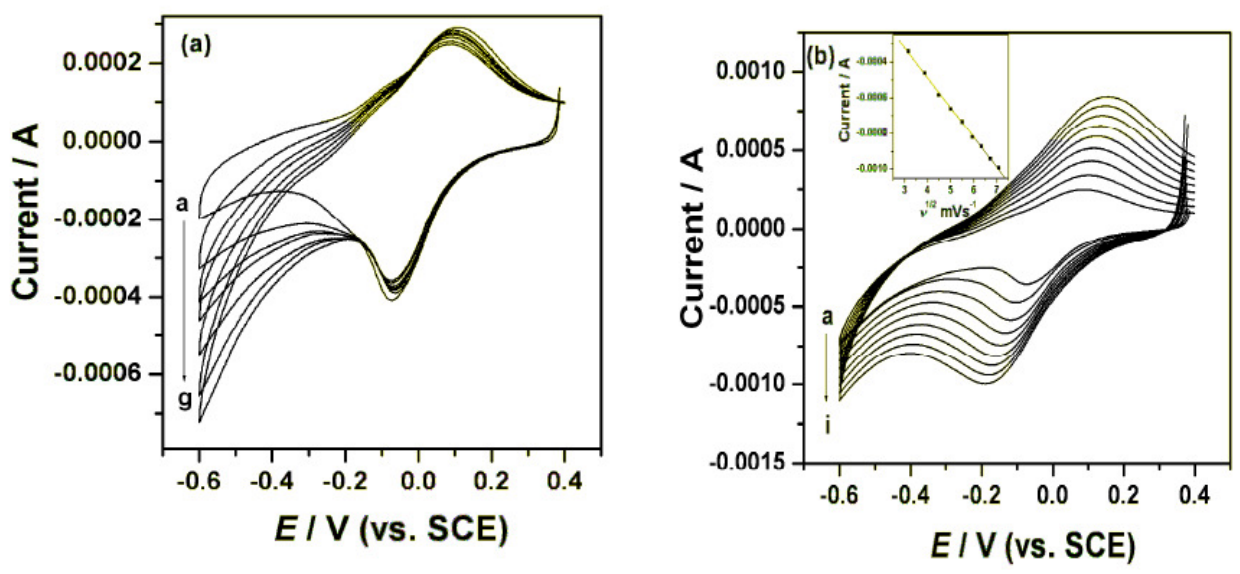

Figure 5. Cyclic voltammograms of Gr/carboxylated graphene-(PANI-PSS) (a) for varying $\mathrm{H}_{2} \mathrm{O}_{2}$ concentrations of $0,1,2,3,4,5$ and $6 \mathrm{mM}$ (a-g) in phosphate buffer solution of $\mathrm{pH} 7.0$ containing $0.1 \mathrm{M} \mathrm{KCl}$ at the scan rate of $0.01 \mathrm{Vs}^{-1}$. (b) Cyclic voltammograms at different scan rates (a-f) 0.01, 0.015, 0.02, 0.025, 0.03, 0.035, 0.04, 0.045 and $0.05 \mathrm{Vs}^{-1}$ in a solution containing $6 \mathrm{mM} \mathrm{H}_{2} \mathrm{O}_{2}$. Inset: The calibration curve, plot of Ip vs. (scan rate) $)^{1 / 2}$.

Fig. 5b shows the cyclic voltammograms recorded for $6 \mathrm{mM} \mathrm{H}_{2} \mathrm{O}_{2}$ solution in different scan rates. It is observed that by increasing the sweep rate, the peak potential for the reduction of $\mathrm{H}_{2} \mathrm{O}_{2}$ shifts to more negative values. The peak currents for the cathodic reduction of $\mathrm{H}_{2} \mathrm{O}_{2}$ are proportional to the square root of scan rate, predicting a diffusion controlled process [26]. The inset in the figure 
shows the relation between scan rate and cathodic peak current and the linear regression equation is given by

$$
i_{\mathrm{p}}(C)=1.790 \times 10^{-4}-1.668 \times 10^{-4} v^{1 / 2}\left(\mathrm{Vs}^{-1}\right), R=-0.999 .
$$

\section{Chronoamperometric determination of $\mathrm{H}_{2} \mathrm{O}_{2}$ at Gr/carboxylated graphene-} (PANI-PSS) electrode

Fig. 6a shows the amperogram recorded for the Gr/carboxylated graphene(PANI-PSS) electrode at a working potential of $-0.18 \mathrm{~V}$ with successive additions of $25 \mu \mathrm{M} \mathrm{H}_{2} \mathrm{O}_{2}$ into the $0.1 \mathrm{M}$ phosphate buffer solution at $\mathrm{pH}$ 7.0. The reaction occurring at the $\mathrm{Gr} /$ carboxylated graphene-(PANI-PSS) electrode was very fast, reaching a dynamic equilibrium upon each addition of the analyte with a response time less than 3 s to reach $100 \%$ signal. Such a fast amperometric response time is indicative of faster charge transport on the modified electrode. A wide linear response range from $25 \mu \mathrm{M}$ to $350 \mu \mathrm{M}$ was observed and the linear regression equation is

$$
i_{\mathrm{p}(\mathrm{H} 2 \mathrm{O} 2)}(\mathrm{A})=-1.704 \times 10^{-5}-5.644 \times 10^{-8} C_{(\mathrm{H} 2 \mathrm{O} 2)}(\mu \mathrm{M}), R=0.995
$$
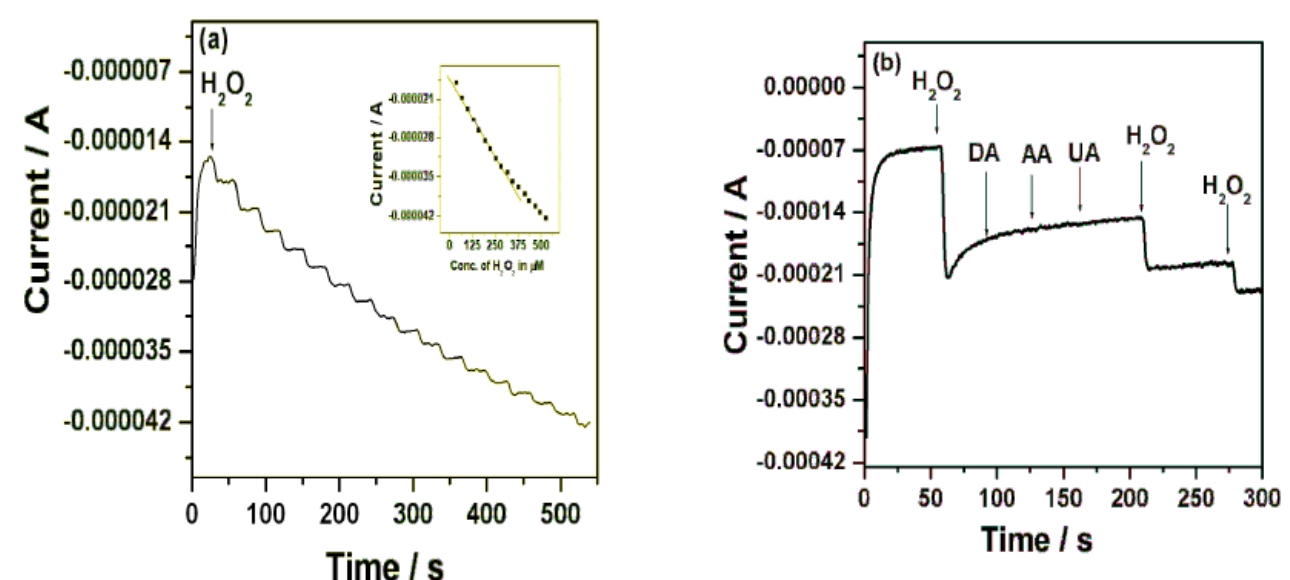

Figure 6. Chronoamperometric response of Gr/carboxylated graphene-(PANI-PSS) electrode for the reduction of $\mathrm{H}_{2} \mathrm{O}_{2}$ at $-0.18 \mathrm{~V}$ in phosphate buffer solution containing $0.1 \mathrm{M} \mathrm{KCl}$ (pH 7.0.). Each addition increased the concentration of $\mathrm{H}_{2} \mathrm{O}_{2}$ by $25 \mu \mathrm{M}(\mathbf{a})$. Inset: plot of $\left[\mathrm{H}_{2} \mathrm{O}_{2}\right]$ vs. catalytic peak current. Amperometric response depicting the effect of coexisting AA, DA and UA on the measurement of $\mathrm{H}_{2} \mathrm{O}_{2}$ at $\mathrm{Gr} /$ carboxylated graphene-(PANI-PSS) (b) at the applied potential of $-0.18 \mathrm{~V}$ in phosphate buffer solution of $\mathrm{pH}$ 7.0. containing $0.1 \mathrm{M} \mathrm{KCl}$.

A sensitivity of $201.4 \mathrm{nA} / \mu \mathrm{M} / \mathrm{cm}^{2}$ was obtained, the detection and quantification limits were estimated at $0.1 \mu \mathrm{M}(S / N=3)$ and $25 \mu \mathrm{M}$, respectively. We investigated the effect of interfering species commonly found in biological samples such as ascorbic acid, dopamine and uric acid, as shown in Fig. 6b. The addition of $\mathrm{H}_{2} \mathrm{O}_{2}$ to the stirred solution shows the increasing current response; however, the addition of interfering species such as AA $(25 \mu \mathrm{M})$, DA $(25 \mu \mathrm{M})$ and UA $(25 \mu \mathrm{M})$ did not show any increase in current response. The accelerated electron transfer reaction due to the presence of graphene and PANI-PSS composite allows $\mathrm{H}_{2} \mathrm{O}_{2}$ detection at a very low potential, indicating high 
selectivity towards $\mathrm{H}_{2} \mathrm{O}_{2}$. Various $\mathrm{H}_{2} \mathrm{O}_{2}$ sensors have been reported in the literature. However, it is very difficult to compare one sensor to other because the performance of the sensor is greatly dependent on the applied potential, supporting electrolyte, electrode material and its surface area. Different $\mathrm{H}_{2} \mathrm{O}_{2}$ sensors are summarized in Table 2 with respect to operating conditions, sensitivity and the detection limit: it can be seen that the performance of the developed sensor is comparable to most of $\mathrm{H}_{2} \mathrm{O}_{2}$ sensors reported in the literature [27-32].

Table 2. Comparison of the Gr/ carboxylated graphene-(PANI-PSS) electrode with other reported biosensors.

\begin{tabular}{|c|c|c|c|c|c|}
\hline $\mathrm{H}_{2} \mathrm{O}_{2}$ biosensor & $\begin{array}{l}\text { Applied potential } \\
\text { (V vs. SCE) }\end{array}$ & Electrolyte & $\begin{array}{c}\text { Detection } \\
\text { limit }(\mu M)\end{array}$ & $\begin{array}{l}\text { Response } \\
\text { time (s) }\end{array}$ & References \\
\hline $\mathrm{Co}_{3} \mathrm{O}_{4}$ nanowall electrode & -0.2 (vs. $\mathrm{Ag} / \mathrm{AgCl})$ & $0.01 \mathrm{M}$ PBS & - & - & {$[18]$} \\
\hline TN/DNA/nanoTiO $2 /$ GCE & -0.2 (vs. $\mathrm{Ag} / \mathrm{AgCl})$ & PBS & 50 & - & [19] \\
\hline $\begin{array}{l}\mathrm{Fe}_{2} \mathrm{O}_{3}-\mathrm{Ag} \text { sub microsphere } \\
\text { modified GC electrode }\end{array}$ & $-0.5($ vs. $\mathrm{Ag} / \mathrm{AgCl})$ & $0.2 \mathrm{M}$ PBS & 1.2 & - & [26] \\
\hline $\begin{array}{l}\text { CuO-nanoflower-midified } \\
\text { electrode }\end{array}$ & -0.3 & $0.1 \mathrm{M} \mathrm{NaOH}$ & - & $<10$ & [27] \\
\hline PANI-g-MWCNT-ME & -0.3 & PBS & 0.001 & $<8$ & {$[28]$} \\
\hline $\mathrm{GO} / \mathrm{MnO}_{2}$ & -0.3 & $0.1 \mathrm{M} \mathrm{NaOH}$ & 0.8 & $<5$ & [29] \\
\hline PANi-SWCNTs/Pt & -0.3 & $0.1 \mathrm{M}$ PBS & 1.2 & $<4$ & [30] \\
\hline $\begin{array}{l}\mathrm{Fe} 3 \mathrm{O} 4 / \mathrm{CS}-\mathrm{Hb}-\mathrm{Fe} 3 \mathrm{O} 4 / \mathrm{CS}- \\
\text { GCE }\end{array}$ & -0.15 & $0.15 \mathrm{M}$ PBS & 4 & - & {$[31]$} \\
\hline $\begin{array}{l}\text { Gr/carboxylated graphene- } \\
\text { (PANI-PSS) }\end{array}$ & -0.18 & $0.1 \mathrm{M}$ PBS & 1.0 & $<3$ & $\begin{array}{c}\text { Present } \\
\text { work }\end{array}$ \\
\hline
\end{tabular}
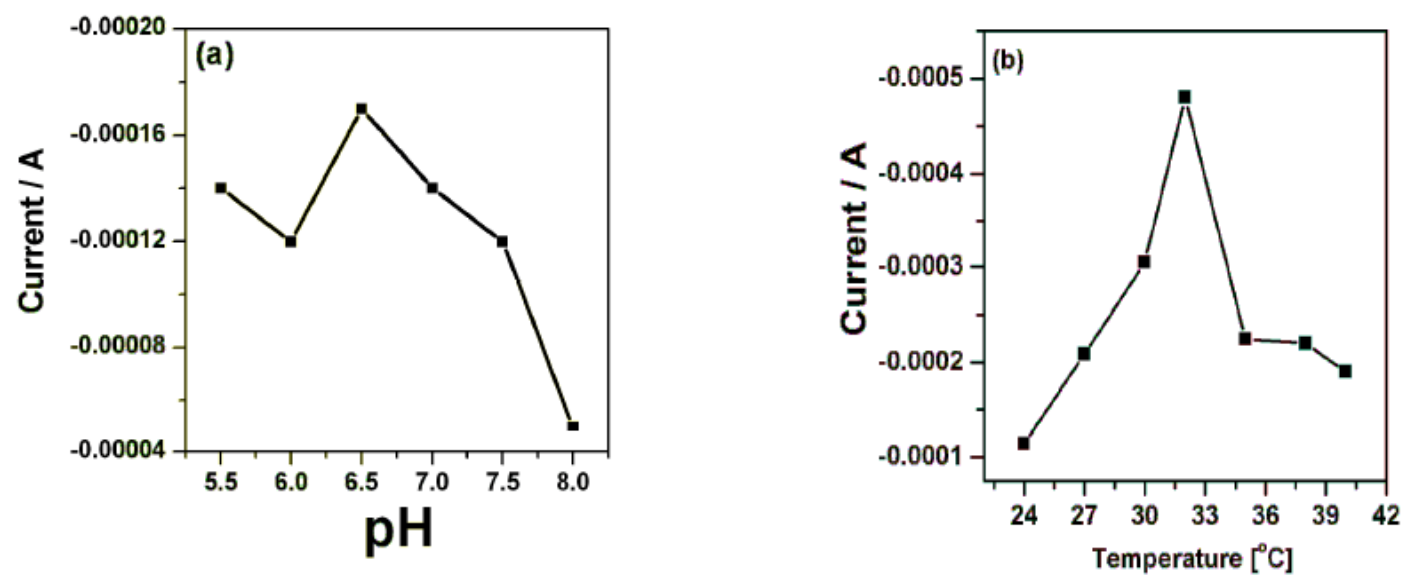

Figure 7. Influence of $\mathrm{pH}$ on the response of the Gr/carboxylated graphene-(PANIPSS) electrode; (a) Effect of temperature on the response of the modified electrode, (b) in phosphate buffer solution containing $0.1 \mathrm{M} \mathrm{KCl}$ of $\mathrm{pH} 7.0$ containing $1 \mathrm{mM} \mathrm{H}_{2} \mathrm{O}_{2}$.

\section{Effect of pH and temperature on the behavior of Gr/carboxylated graphene- (PANI-PSS) electrode}

The effect of $\mathrm{pH}$ of $\mathrm{Gr} / \mathrm{carboxylated}$ graphene-(PANI-PSS) electrode was investigated under constant $\mathrm{H}_{2} \mathrm{O}_{2}$ concentration $(1 \mathrm{mM})$ for the range of 5.5 to 8.0. Fig. 7a shows that the current increases with increase in $\mathrm{pH}$ value and reaches a maximum value at $\mathrm{pH}$ 6.5. At higher $\mathrm{pH}$ (7.0 to 8.0) the electrocatalytic activity of the electrode was decreased. Since the physiological $\mathrm{pH}$ value is about 7.0, we chose $\mathrm{pH} 7.0$ in the electrochemical detection of $\mathrm{H}_{2} \mathrm{O}_{2}$. The effect of temperature on the activity of the modified electrode was determined at $\mathrm{pH}$ 7.0. 
When the temperature was increased from $24{ }^{\circ} \mathrm{C}$ to $40{ }^{\circ} \mathrm{C}$ the response increased, due to faster reaction and analyte diffusion and then started to decrease. The temperature at which the modified electrode yielded a maximum current was found to be at $32{ }^{\circ} \mathrm{C}$, as shown in Fig. $7 \mathrm{~b}$.

\section{Stability and reproducibility}

Long term stability is one of the most important requirements of biosensors. The stability of Gr/carboxylated graphene-(PANI-PSS) electrode was checked in the presence of $1 \mathrm{mM} \mathrm{H}_{2} \mathrm{O}_{2}$ by performing amperometric experiment in $0.1 \mathrm{M}$ PBS of $\mathrm{pH} 7$ at an applied potential of $-0.18 \mathrm{~V}$ under stirring condition for a period of 1800 s. Fig. 8 shows that the decrease of current observed was only around 3\% even in stirring condition indicating that the modified electrode is stable and suitable for sensor application. The modified electrode showed an acceptable repeatability. The interface was prepared eight times in the same manner and tests were performed in $0.1 \mathrm{M}$ phosphate buffer of $\mathrm{pH}$ 7.0. A relative standard deviation lower than $5 \%$ was obtained, indicating the good repeatability of the sensor.

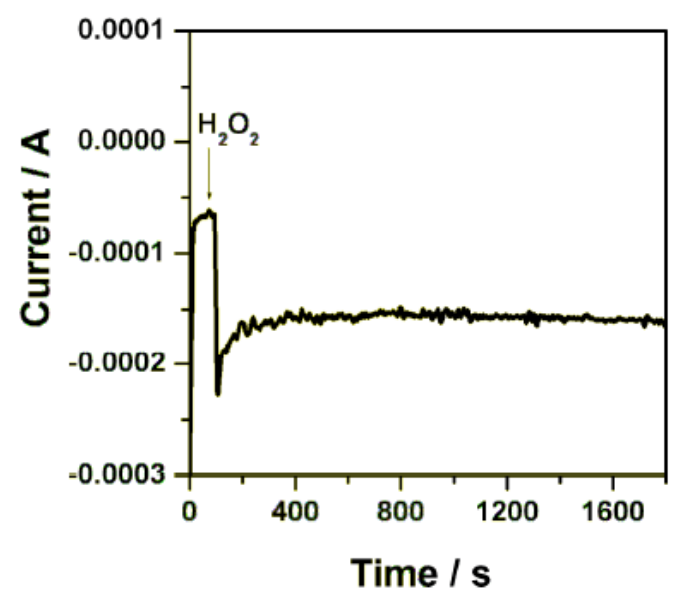

Figure 8. Stability of the current response of $1 \mathrm{mM} \mathrm{H}_{2} \mathrm{O}_{2}$ at $\mathrm{Gr} /$ carboxylated graphene(PANI-PSS) at the applied potential of $-0.18 \mathrm{~V}$ in phosphate buffer solution containing $0.1 \mathrm{M} \mathrm{KCl}$ of $\mathrm{pH} 7.0$.

\section{Real sample analysis}

Hydrogen peroxide is used as preservative or decolourant in food industry and as additive in production of cosmetics. To investigate the actual applicability of the developed biosensor Gr/carboxylated graphene-(PANI-PSS) to practical usage, the real sample was examined. The sample which is used in beauty salon for hair coloring was labeled to contain $6 \% \mathrm{w} / \mathrm{v}$ of $\mathrm{H}_{2} \mathrm{O}_{2}$. The test was carried out in 0.1 M PBS containing different aliquots of $0.1 \mathrm{M}$ of the sample by an amperometric method. The real samples were diluted according to working range of Gr/carboxylated graphene-(PANI-PSS), the current response from each real sample at an applied potential of $-0.18 \mathrm{~V}$ was measured. The concentration of the real sample analysis was then determined by interpolation on the linear range of calibration curves of $\mathrm{H}_{2} \mathrm{O}_{2}$. The results obtained for the reduction of $\mathrm{H}_{2} \mathrm{O}_{2}$ in commercial sample were compared with those of Gr/carboxylated graphene- 
(PANI-PSS) electrodes for standard $\mathrm{H}_{2} \mathrm{O}_{2}$ and are tabulated in Table 3; this provides good approval for suitability of the electrode in the development of a reliable reproducible biosensor.

Table 3. Determination of $\mathrm{H}_{2} \mathrm{O}_{2}$ used for hair dye solution ( $\left.n=5\right)$ with the $\mathrm{Gr} /$ carboxylated graphene-(PANI-PSS) electrode.

\begin{tabular}{lcccc}
\hline Sample & $\begin{array}{c}\mathbf{H}_{2} \mathbf{O}_{\mathbf{2}} \text { (added) } \\
(\mathbf{m M} / \mathbf{L})\end{array}$ & $\begin{array}{c}\text { Found } \\
(\mathbf{m M} / \mathbf{L})\end{array}$ & Recovery (\%) & RSD (\%) \\
\hline 1 & 3 & 2.98 & 99.3 & 2.64 \\
2 & 4 & 4.97 & 99.5 & 1.82 \\
3 & 5 & 4.9 & 98 & 3.53 \\
4 & 6 & 5.9 & 98.3 & 2.67 \\
\hline
\end{tabular}

\section{Conclusions}

In this work, the electrocatalytic reduction of $\mathrm{H}_{2} \mathrm{O}_{2}$ at $\mathrm{Gr} /$ carboxylated graphene(PANI-PSS) electrode was investigated. An over potential diminution is achieved at the modified electrode at $\mathrm{pH} 7.0$ with higher electron transfer kinetics. The electrochemical reduction of $\mathrm{H}_{2} \mathrm{O}_{2}$ is a diffusion controlled process. The modified electrode also offers stable amperometric detection of $\mathrm{H}_{2} \mathrm{O}_{2}$ at a lower applied potential of $-0.18 \mathrm{~V}$ with a linear range from $25 \mu \mathrm{M}$ to $350 \mu \mathrm{M}$ and the detection limit was found to be $1.0 \mu \mathrm{M}$. The modified electrode showed diminished response from its interferences and the surface fouling was not observed during voltammetric and amperometric measurement of $\mathrm{H}_{2} \mathrm{O}_{2}$.

\section{Acknowledgements}

The authors gratefully thank Sri. A.V.S. Murthy honorary secretary, Rashtreeya Sikshana Samiti Trust, Bangalore, and Dr. P. Yashoda, Principal, S.S.M.R.V. Degree College, Bangalore, for their continuous support and encouragement. S. Prasanna Kumar personally thanks Fr. Roshan Lobo, Principal, St. Joseph's Pre-University College, Bangalore for his support and encouragement. R. Manjunatha acknowledges the financial support from Department of Atomic Energy - Board of Research in Nuclear Sciences (DAE-BRNS), Government of India.

\section{References}

1. Zhou K, Zhu Y, Yang X, Luo J, Li C, Luan S. Electrochim Acta. 2010;55:3055.

2. $\quad$ Wang Y, Li Y, Tang L, Lu J, Li J. Electrochem Comm. 2009;11:889.

3. Shan C, Yang H, Han D, Zhang Q, Ivaska A, Niu L. Biosens Bioelectron. 2010;25:1504.

4. Kumar SP, Manjunatha R, Nethravathi C, Suresh GS, Rajamathi M, Venkatesha TV. Electroanalysis. 2011;23:842.

5. Shan C, Yang H, Han D, Zhang Q, Ivaska A, Niu L. Biosens Bioelectron. 2010;25:1070.

6. Taguchi S, Tanaka T. J Power Sources. 1987;20:249.

7. Panero S, Prosperi P, Bonino F, Scrosati B, Corradini A, Mastragostino M. Electrochim Acta. 1987;32:1007.

8. Valente AJM, Burrows HD, Lobo VMM. Colloids Surf A: Physicochem Eng Aspects. 2006;275:221. 
9. Granot E, Basnar B, Cheglakov Z, Katz E, Willer I. Electroanalysis. 2006;18:26.

10. Mu S, Xue H. Sens Actuat B. 1996;31:155.

11. Shaolin M, Jinqing K, Jianbing Z. J Electroanal Chem. 1992;334:121.

12. Kocherginsky NM, Wang Z. J Electroanal Chem. 2007;611:162.

13. Liu X, Luo L, Ding Y, Xu Y, Li F. J Solid State Electrochem. In press. DOI: 10.1007/s10008-010-1120-y.

14. Yang Y, Yang G, Huang Y, Bai H, Lu X. Colloids Surf A: Physicochem Eng Aspects. 2009;340:50.

15. Upadhyay AK, Ting TW, Chen SM. Talanta. 2009;79:38.

16. Luo X, Killard AJ, Morrin A, Smyth MR. Anal Chim Acta. 2006;575:39.

17. Liu A, Dong W, Liu E, Tang W, Zhu J, Han J. Electrochim Acta. 2010;55:1971.

18. Jia W, Guo M, Zheng Z, Yu T, Rodriguez EG, Wang Y, Lei Y. J Electroanal Chem. 2009;625:27.

19. Lo PH, Kumar SA, Chen SM. Colloids Surf B: Biointerfaces. 2008;66:266.

20. Liu Z, Zhao B, Shi Y, Guo C, Yang H, Li Z. Talanta. 2010;81:1650.

21. Nethravathi C, Rajamathi M. Carbon. 2008;46:1994.

22. Su CY, Xu Y, Zhang W, Zhao J, Liu A, Tang X, Tsai CH, Huang Y., Li LJ. ACS Nano. 2010;4:5285.

23. Gilje S, Han S, Wang M, Wang KL, Kaner RB. Nano Lett. 2007;7:3394.

24. Chen WC, Wen TCN, Gopalan A. J Electrochem Soc. 2004;151:F242.

25. Liu A, Wei M, Honma I, Zhou H. Adv Funct Mater. 2006;16:371.

26. Simon BP, Fabregas E. Biosens Bioelectron. 2006;22:131.

27. Liu Z, Zhao B, Shi Y, Guo C, Yang H, Li Z. Talanta. 2010;81:1650.

28. Song MJ, Hwang SW, Whang D. Talanta. 2010;80:1648.

29. Santhosh P, Manesh K.M, Gopalan A, Lee KP. Anal Chim Acta. 2006;575:32.

30. Li L, Du Z, Liu S, Hao Q, Wang Y, Li Q, Wang T. Talanta. 2010;82:1637.

31. Wang Q, Yun Y, Zheng J. Microchim Acta. 2009;167:153.

32. Tan XC, Zhang JL, Tan SW, Zhao DD, Huang ZW, Mi Y, Huang ZY. Sensors. 2009;9.6185. 